\title{
Salivary and Serum IgA Evaluation of Patients with Oro-Facial Squamous Cell Carcinoma
}

\author{
Taye J. Lasisi ${ }^{1}$, Bidemi O. Yusuf ${ }^{2}$, Olawale A. Lasisi $^{3}$, Efiong E. U. Akang ${ }^{4}$ \\ ${ }^{1}$ Department of Physiology, College of Medicine, University of Ibadan, Ibadan, Nigeria \\ ${ }^{2}$ Department of Epidemiology and Biostatistics, College of Medicine, University of Ibadan, Ibadan, Nigeria \\ ${ }^{3}$ Department of Otorhinolaryngology, University of Ibadan, Ibadan, Nigeria \\ ${ }^{4}$ Department of Pathology, University of Ibadan, Ibadan, Nigeria \\ Email: jameelahlasisi@yahoo.com
}

Received September 26, 2012; received October 30, 2012; accepted November 10, 2012

\begin{abstract}
Objective: To evaluate salivary and serum levels of Immunoglobulin A (IgA) in patients with oro-facial squamous cell carcinoma. Methods: This is a cross sectional study. Patients with oro-facial squamous cell carcinoma attending the Oral Pathology and Radiotherapy clinics of the University College Hospital, Ibadan, Nigeria were included. Seventy subjects comprising 22 patients with untreated OSCC, 18 patients with OSCC receiving treatment and 30 healthy, age and gender matched individuals were included. Serum and salivary samples from the participants were analysed for IgA levels using ELISA technique. Results: The mean value of serum IgA in OSCC patients receiving treatment was significantly lower compared with healthy controls $(p=0.03)$, while no significant difference was observed comparing untreated OSCC patients with treated and healthy controls. The salivary IgA levels did not show any significant difference between the three groups $(\mathrm{p}=0.73)$. Also, there was no correlation between serum and salivary levels of $\operatorname{IgA}$ among the subjects. Conclusions: Serum IgA appeared to be better index than salivary IgA levels in monitoring response to treatment in patients with oro-facial carcinoma.
\end{abstract}

Keywords: Saliva; Serum; Immunoglobulin; Oro-Facial Squamous Cell Carcinoma

\section{Introduction}

Squamous cell carcinoma represents the most common malignant tumours of the oro-facial region [1]. Oro-facial cancers constitute the major cancers of the head and neck region which is the 10th most common cancer in humans $[2,3]$. However, the prognosis of these cancers has remained relatively unchanged for the past years despite advances in diagnosis and management [4].

Care for patients with oro-facial squamous cell carcinoma includes curative and palliative measures that are planned to re-establish and improve the quality of life of these individuals. The various measures are designed to improve diagnosis, treatment, control of disease progression and monitoring. Patients with oro-facial cancers are subjected to radiotherapy or chemotherapy, or both. These forms of treatments are immunosuppressive and consequently interfere with the function of various organs and systems including the endocrine and immune systems. As a consequence, these patients require routine clinical evaluation because of the effect of the disease and the treatments on the body system especially the body immune system.

Immuoglobulin A $(\operatorname{IgA})$ is the 2 nd most common se- rum immunoglobulin and the major and predominant class of immunoglobulin in secretions like saliva, tears colostrum, and mucus [5]. Since it is found predominantly in secretions, secretory $\operatorname{IgA}$ is important in local (mucosal) immunity.

Most alterations in the body systems are generally measured in blood although saliva as a biologic fluid is emerging as an important and useful medium to evaluate physiologic alterations in health and diseases [6,7]. Salivary assessment has added advantages over blood because of its non invasiveness, simple and easier collection with less discomfort.

Salivary analysis holds promise as a non-invasive approach to identify biomarkers for oro-facial malignancies. Salivary levels of immunoglobulins may have significant value in oro-facial cancer diagnostics and monitoring. This study aimed at evaluating the levels of salivary and serum IgA in patients with oro-facial squamous cell carcinoma in relation to levels in healthy individuals.

\section{Methodology}

\subsection{Study Design}

A cross-sectional study using convenient sampling con- 
ducted between January 2009 and December 2009

\subsection{Study Population}

Ethical clearance was received from UI/UCH Institutional Ethics Review Committee (UI/EC/09/0114) and informed consent was obtained from each participant. The study population included 22 patients with oro-facial OSCC attending the Dental and Radiotherapy Clinics of the University College Hospital, Ibadan. The biodata and clinical data of the subjects were obtained through a self administered proforma. In this study OSCC included squamous cell carcinoma affecting the lips, tongue, buccal mucosa, palate, alveolus, as specified in the International Classification of Disease for Oncology (ICD-10 codes C00.2 - C06) [8]. Samples from thirty healthy individuals (age and gender matched) and eighteen patients being treated with radiotherapy with chemotherapy were included as controls. None of the participants in the OSCC group had history of any underlying systemic illness, immunodeficiency and autoimmune disorders. Each healthy individual underwent a face and mouth examination by the investigator (TJL) to ensure that suspicious mucosal lesions, as well as acute and chronic periodontitis were not present. All healthy control individuals had not received any medication one month prior to the study. None of the healthy controls had a history of any chronic disease, prior malignancy, immunodeficiency and autoimmune disorders. All patients and controls gave informed consent.

\subsection{Screening and Diagnosis of OSCC}

Clinical examination was carried out with the subjects seated in the clinic and biopsy procedure performed by TJL. Histological diagnosis was also performed by TJL in the Oral Pathology laboratory.

\subsection{Collection of Saliva Sample}

Whole non stimulated saliva was collected by asking participants to spit into a graduated universal bottle for a period of 10 minutes. This was immediately transferred to sterilized tubes and frozen. The samples were stored at $-20^{\circ} \mathrm{C}$ until the time for immunoglobulin measurement.

\subsection{Collection of Blood Sample}

Blood was collected simultaneously from peripheral veins in the upper arm using a size $21 \mathrm{G}$ needle on a $5 \mathrm{ml}$ disposal syringe after cleaning the area with methylated spirit swab. Samples were collected in EDTA bottles.

The samples were centrifuged for 15 minutes at 2000 rpm and plasma was separated from the cellular components using a plastic Pasteur pipette and stored at $-20^{\circ} \mathrm{C}$ prior to use. The plasma was used for the analysis.

\subsection{Quantification of IgA}

The samples stored in the freezer were thawed in a refrigerator for 18 hours (to preserve the immunoglobulin) and then centrifuged at $8000 \mathrm{rpm}$ for 15 minutes.

IgA in the samples was quantified using the Enzyme Linked Immunosobent Assay (ELISA) method (IC Lab Inc. USA, E-80A Lot \# 5).

Assay Protocol: Each test sample was diluted into $1 / 10,000.100 \mu \mathrm{L}$ of 6 standards were dispensed in duplicate with pipette into pre designated wells. The micro titre plate was incubated at room temperature for thirty $(30 \pm 2)$ minutes. Following incubation, the contents of the wells were aspirated. Each well was completely filled with appropriately diluted Wash Solution and aspirate. This was repeated three times. The wells were completely filled with wash buffer. The plate was inverted and the contents were poured out in a waste container. This was followed by sharply striking the wells on absorbent paper to remove residual buffer. This was repeated 3 times for a total of four washes. $100 \mu \mathrm{L}$ of appropriately diluted Enzyme-Antibody Conjugate was transferred to each well using pippette. This was incubated at room temperature for thirty $(30 \pm 2)$ minutes. The plate was kept covered in the dark and levelled during incubation. The wells were washed and blotted as previously described. $100 \mu \mathrm{L}$ of TMB Substrate Solution was transferred into each well using pippette. The wells were incubated in the dark at room temperature for precisely 10 minutes. After 10 minutes, $100 \mu \mathrm{L}$ of Stop Solution was added to each well. The absorbance (450 nm) of the contents of each well was determined and the plate reader was calibrated.

Data analysis: The main outcome variables were the serum and salivary levels of $\operatorname{IgA}$ in patients with oro-facial squamous cell carcinoma and healthy controls. The data was initially explored using the version 16 of the Statistical Package for Social Sciences (SPSS16). For serum IgA levels, means $\pm \mathrm{SD}$ and ranges were calculated while for salivary IgA levels, Logarithm values were used to calculate mean values because data was not normally distributed. Test of significance in comparing these variables was done using one-way analysis of variance test (ANOVA) with Dunnett's T post Hoc test as appropriate. Salivary and serum immunoglobulins were correlated using Pearson's correlation test. The level of significance was set at $5 \%(\mathrm{p}<0.05)$ for all analyses.

\section{Results}

The study participants were 70 subjects; these comprised of 22 subjects with untreated OSCC, 18 subjects undergoing treatment (treated OSCC) and 30 healthy controls (Table 1).

The serum mean IgA values in the untreated OSCC 
Table 1. Demographic distribution of subjects and controls.

\begin{tabular}{cccc}
\hline Variable & $\begin{array}{c}\text { Untreated OSCC Healthy Control Treated OSCC } \\
(\mathrm{n}=22)\end{array}$ & $\begin{array}{c}\text { T }=30) \\
(\mathrm{n}=18)\end{array}$ \\
\hline Male & 10 & 13 & 12 \\
Female & 12 & 17 & 6 \\
Mean age \pm SD & $56 \pm 16.3$ years & $50 \pm 10.9$ years & $49 \pm 6.7$ years \\
\hline
\end{tabular}

patients, treated OSCC patients and healthy controls were $368 \pm 89.2 \mathrm{mg} / \mathrm{dl}, 328.3 \pm 90.9 \mathrm{mg} / \mathrm{dl}$ and $390.3 \pm$ $52 \mathrm{mg} / \mathrm{dl}$ respectively (Table 2), while the mean salivary IgA logarithm value of the untreated OSCC subjects was $2.02 \pm 0.47 \mathrm{mg} / \mathrm{dl}$ while the treated OSCC subjects and healthy controls showed salivary IgA mean values of 1.9 $\pm 0.43 \mathrm{mg} / \mathrm{dl}$ and $1.99 \pm 0.56 \mathrm{mg} / \mathrm{dl}$ respectively. Analysis of variance (ANOVA) test showed a significantly lower mean serum IgA in treated OSCC patients compared with healthy controls $(p=0.03)$ and no significant difference $(p=0.73)$ in the mean values of salivary $\operatorname{IgA}$ among the groups (Table 3 ).

\section{Discussion}

The finding from this study showed that serum IgA concentrations are lower in patients with oro-facial carcinoma undergoing treatment compared to untreated group. This may suggest that total serum IgA may be reducing as response to treatment; it may also suggest that the treatment (radiotherapy and chemotherapy) probably leads to reduction in production of immunoglobulins as consequence of suppression of bone marrow activities. The other factors which may be contributory to the lower IgA level among patients on treatment is malnutrition which may follow reduced intake due to nausea, vomiting and the catabolic effect of the treatment $[9,10]$. Slow recovery of cellular and humoral immune parameters generally occurs after antineoplasic treatments [9] and the finding of reduced serum IgA levels in the present investigation suggests that components of the humoral immunity were affected by treatment, a fact that significantly contributed to immunosuppression. As the reduction in serum IgA observed in patients with OSCC occurred before treatment, it seems clear that the presence of cancer itself influenced the decrease. This occurrence may explain the increased level of infections in OSCC patients. The clinical significance of this finding is also that measures that will boost immunity such as nutrient and immunoglobulins supplementation should be incurporated in the management of these patient for good recovery. However, our finding is contrary to that of others $[10,11]$ who reported elevated levels of serum $\operatorname{IgA}$, in oral cancer patients compared with healthy controls. The increased level of serum IgA was attributed to the secretory components of immunoglobulin present in the epithelial cells with subsequent diffusion into the circulation.
The difference in the findings may be attributed to variations in the studied population and analytical methods employed by individual authors.

The present results also demonstrated that mean salivary IgA concentrations in patients with oro-facial squamous cell carcinoma is not different compared with those receiving treatment and healthy individuals. In addition, correlation between IgA levels in serum and saliva of studied individuals showed no significant relationship. Saliva is a physiologic body fluid whose composition is greatly influenced by many factors $[12,13]$ and this may contribute to its inability to indicate the blood levels of serum $\operatorname{IgA}$. Some investigators reported that salivary levels of some biomarkers do not serve as indicators of blood levels [9]. Measurement of biologic markers that demonstrate changes in diseases in saliva must fulfil some requirements. It should properly reflect serum concentration of the marker, correlation between serum and salivary level of the marker should be as high as possible and concentrations of the marker in saliva should not be altered by intra oral conditions or processes involved in marker transport from serum into saliva. Hence, the results of this study indicate that there does not appear to be any correlation between serum and Salivary immunoglobulins. This finding agrees with that of Vinzenks $e t$ al. [14] which showed no correlation between serum IgA levels and saliva IgA levels in oralcancer patients. This may suggest that extravascular transfer of immunoglobulin A primarily depends on the mucosal status of the individual and not necessarily the serum level.

Table 2. Serum IgA levels in $\mathrm{mg} / \mathrm{dl}$ among subjects with untreated Oro-Facial Squamous Cell Carcinoma, treated Oro-Facial Squamous Cell Carcinoma and healthy controls.

\begin{tabular}{cccc}
\hline Subjects & Number & \multicolumn{2}{c}{ Serum IgA (mg/dl) } \\
\hline Untreated OSCC & 22 & $368.7 \pm 89.2$ & $0.2-400$ \\
Treated OSCC & 18 & $328.3 \pm 90.9$ & $70-400$ \\
Normal healthy controls & 30 & $390.5 \pm 52$ & $115-400$ \\
\hline
\end{tabular}

$\mathrm{p}=0.03$.

Table 3. Salivary IgA levels ${ }^{*}$ in $\mathrm{mg} / \mathrm{dl}$ among subjects with untreated Oro-Facial Squamous Cell Carcinoma, treated Oro-Facial Squamous Cell Carcinoma and healthy controls.

\begin{tabular}{cccc}
\hline Subjects & Number & \multicolumn{2}{c}{ Salivary Ig A (mg/dl) } \\
\hline & & Mean \pm SD & Range \\
\hline Untreated OSCC & 22 & $2.02 \pm 0.47$ & $1.1-2.6$ \\
Treated OSCC & 18 & $1.9 \pm 0.43$ & $1.1-2.6$ \\
Normal healthy controls & 30 & $2.0 \pm 0.56$ & $0.4-2.6$ \\
\hline
\end{tabular}

${ }^{*}$ Logarithm values, $\mathrm{p}=0.73$, OSCC: Oro-Facial Squamous Cell Carcinoma. 
Different authors have reported varying results on the concentrations of salivary IgA in patients with oral squamous cell carcinoma. Some authors $[15,16]$ reported elevated salivary IgA in subjects with oral squamous cell carcinoma compared with healthy controls. The increased titers of salivary IgA observed in their studies were attributed to a possible local antibody response to tumor because transudation of serum IgA to saliva is responsible for only a minute amount of total salivary IgA. In contrast, Shpitzer et al. [17] reported a significant reduction of salivary $\operatorname{IgA}$ in oral squamous carcinoma patients compared with healthy individuals. It was suggested that the significant reduction may be attributed to a local or regional immune suppression as evidenced by increased susceptibility of oral cancer patients to infections. The variations in the findings of individual authors also indicate that salivary IgA concentration is probably not a reliable marker in oral cancer patients.

In conclusion, the finding from this study may suggest that serum $\operatorname{IgA}$ appeared to be better index than salivary IgA levels in monitoring response to treatment in patients with oro-facial carcinoma. However, long term longitudinal studies with a large population are needed to validate these findings.

\section{REFERENCES}

[1] S. Silverman Jr., "Demographics and Occurrence of Oral and Pharyngeal Cancers. The Outcome, the Trends, the Challenge," The Journal of the American Dental Association, Vol. 132, No. 1, 2001, pp. 7s-11s.

[2] B. F. Adeyemi, L. V. Adekunle, B. M. Kolude, E. E. U. Akang and J. O. Lawoyin, "Head and Neck Cancer-A Clinicopathological Study in a Tertiary Care Centre," Journal of the National Medical Association, Vol. 100, No. 6, 2008, pp. 690-697.

[3] E. C. Otoh, N. W. Johnson, I. S. Danfillo, O. A. Adeleke and H. A. Olasoji, "Primary Head and Neck Cancers in North Eastern Nigeria," West African Journal of Medicine, Vol. 23, No. 4, 2004, pp. 305-313.

[4] B. W. Neville and T. A. Day, "Oral Cancer and Precancerous Lesions," CA: Cancer Journal for Clinicians, Vol. 52, No. 4, 2002, pp. 195-215. doi:10.3322/canjclin.52.4.195

[5] M. Gene, "Immunoglobulins-Structure and Function," Microbiology and Immunology On-Line, University of Carolina School of Medicine.

[6] S. J. Farnaud, O. Kosti, S. J. Getting and D. Renshaw, "Saliva: Physiology and Diagnostic Potential in Health and Disease," Scientific World Journal, Vol. 10, 2010, pp. 434-456. doi:10.1100/tsw.2010.38

[7] M. Navazesh, "Saliva in Health and Disease," Journal of the California Dental Association, Vol. 39, No. 9, 2011, pp. 626-628.

[8] C. D. Donaldson, R. H. Jack, H. Moller and M. Luchtenborg, "Oral Vavity, Pharyngeal and Salivary Gland Cancer. Disparities in Ethnicity-Specific Incidence among London Population," Oral Oncology, Vol. 48, No. 9, 2012, pp. 799-802. doi:10.1016/j.oraloncology.2012.03.005

[9] G. T. Kovacs, O. Barany and O. Schlck, "Late Immune Recovery in Children Treated for Malignant Disease," Pathology \& Oncology Research, Vol. 14, No. 4, 2008, pp. 391-397. doi:10.1007/s12253-008-9073-5

[10] S. Parveen, N. Taneja, R. J. Bathi and A. C. Deka, "Evaluation of Circulating Immune Complexes and Serum Immunoglobulins in Oral Cancer Patients-A Follow up Study," Indian Journal of Dental Research, Vol. 21, No. 1, 2010, pp. 10-15. doi:10.4103/0970-9290.62800

[11] N. N. Khanna, S. N. Das and S. Khanna, "Serum Immunoglobulins in Squamous Cell Carcinoma of the Oral Cavity," Journal of Surgical Oncology, Vol. 20, No. 1, 1982, pp. 46-48. doi:10.1002/jso.2930200111

[12] C. Dawes, "Salivary Flow Patterns and Health of Hard and Soft Oral Tissues," The Journal of the American Dental Association, Vol. 139, No. 2, 2008, pp. 18s-24s.

[13] P. D. de Almeida, A. M. Gregio, M. A. Machado, A. A. de Lima and L. R. Azevedo, "Saliva Composition and Functions: A Comprehensive Review," Journal of Contemporary Dental Practice, Vol. 9, No. 3, 2008, pp. 72-80.

[14] K. Vinzenz, R. Pavelka, E. Schönthal and F. Zekert, "Serum Immunoglobulin Levels in Patients with Head and Neck Cancer (IgE, IgA, IgM, IgG)," Oncology, Vol. 43, No. 5, 1986, pp. 316-322. doi:10.1159/000226390

[15] A. M. Brown, E. T. Lally, A. Frankel, R. Harwick, L. W. Davis and C. J. Rominger, "The Association of the IGA Levels of Serum and Whole Saliva with the Progression of Oral Cancer," Cancer, Vol. 35, No. 4, 1975, pp. 11541162 .

doi:10.1002/1097-0142(197504)35:4<1154::AID-CNCR2 820350421>3.0.CO;2-D

[16] A. E. Krasteva, A. Aleksiev and I. Ivanova, "Salivary Components of Treated Cancer Patients and Patients with Precancerous Lesions," Journal of IMAB Annual Proceeding, Vol. 2, No. 2, 2008, pp. 41-43.

[17] T. Shpitzer, G. Bahar, R. Feinmesser and R. M. A. Nagler, "Comprehensive Salivary Analysis for Oral Cancer Diagnosis," Journal of Cancer Research and Clinical Oncology, Vol. 133, No. 9, 2007, pp. 613-617. doi:10.1007/s00432-007-0207-Z 